\title{
LA CONSTRUCCIÓN SOCIAL DE LA PARENTALIDAD Y LOS PROCESOS DE VINCULACIÓN Y DESVINCULACIÓN PADRE - HIJO. EL PAPEL DEL MEDIADOR FAMILIAR.
}

\author{
THE SOCIAL CONSTRUCTION OF PARENTHOOD \\ AND THE PROCESSES OF BONDING AND UNBINDING BETWEEN FATHER \\ AND SON. THE ROLE OF THE FAMILY MEDIATOR.
}

\author{
Fermín Romero Navarro \\ Universidad de Las Palmas de Gran Canaria (España)
}

\begin{abstract}
Resumen: La familia es una institución social básica sometida a profundos y acelerados cambios que afectan a elementos esenciales de la misma, hasta ahora considerados como permanentes e intocables, como son entre otros la figura del padre como eje vertebrador de la unidad familiar. La conflictividad conyugal y/o de pareja que se salda con la ruptura demanda un tipo de soluciones en las que las funciones parentales y las relaciones existentes entre padres e hijos, y de forma especial las existentes entre el padre varón e hijos, quedan cuestionadas o al menos sometidas a procesos de readaptación. ¿Qué es lo que hace que un varón se constituya en padre de unos hijos?; ¿qué es aquello que se lo impide?; ¿qué y cómo se vinculan estas dos figuras: padre e hijo?; ¿a qué dinámica queda sometida la figura del padre en los procesos de separación y divorcio?; ¿qué resonancias tienen estas cuestiones en los procesos de mediación familiar? La mediación familiar es un método de resolución de conflictos que interviene en un escenario familiar complejo, transido por la disolución y la separación de vínculos emocionales y afectivos, los cuales a su vez tienen que ver con procesos identitarios de los miembros afectados. En este escenario, la figura del padre y sus funciones familiares se pueden ver cuestionadas, sin que haya mediado previamente una posición crítica al respecto, más bien se corre el riesgo de que en dicho escenario se reproduzcan, a modo de resonancias, las construcciones sociales que en torno a la paternidad existen en el imaginario social, dándose lugar a una inadecuada intervención mediadora. Estas cuestiones brevemente planteadas, y dentro de la perspectiva de las funciones del mediador familiar, son las que se abordan en el presente artículo.
\end{abstract}

Palabras claves: Paternidad/ Vinculación parento-filial/ Divorcio emocional/ Alienación parental/ Mediación Familiar

\begin{abstract}
Family is a basic social institution subject to deep and fast changes that affect essential elements of itself until now considered as permanent and untouchable as is the father figure to the point of convergence of the family unity. The conjugal or couple conflicts that ends up in the breaking of relations demand a sort of solutions in which the parental functions and the relations between parents and children, and specially the relations between the male parent and the children, are questioned or at least are subject to re-adaptation processes. What is it that makes a man to be a father? What is it that prevents it? What and how are those two figures, father and son, bonded?; To what dynamics the role of the father is subjected in the processes of divorce and separation?; What kind of repercussions have these questions in the processes of family mediation? The family mediation is a method of conflict resolution that takes place in a complex family stage, that is overcome by the dissolution and the separation of the emotional and affective family bonds, which at the same time are implied with the processes of identification of the affected members of the family. In this stage, the figure of the father and its family functions can be questioned without any previous
\end{abstract}

Correspondencia: Fermín Romero Navarro. Doctor en Sociología. Profesor titular de la Universidad de Las Palmas de Gran Canaria. Mediador familiar. Director del Centro de Orientación Familiar de Canarias. fromero@dps.ulpgc.es 
censure position for that matter, it is rather a risk taking position in which stage it happens, as consequences, the social constructions that exist around the paternity in the social imagery, and in that way taking place an inadequate mediation intervention. We pretend to respond to these questions, briefly presented and inside the perspectives of the family mediator's functions, in the present article.

Key words: Parenthood/ Parent-child Relationship/ Emotional divorce/ Parental alienation/ Family Intervention

\section{INTRODUCCIÓN}

Un prestigioso psiquiatra y celebre autor de muchas obras de gran difusión, el doctor Rojas Marcos, relata una singular anécdota en uno de sus libros: En una ocasión en que daba una conferencia a estudiantes universitarios, preguntó quiénes de los jóvenes varones presentes en la sala eran padres. Ninguno de ellos levantó la mano, hecho que le extrañó mucho al citado autor. En otro momento de la conferencia preguntó quiénes de los varones presentes habían dejado embarazada a alguna chica, compañera o novia, y a reglón seguido levantaron la mano bastantes personas.

Este hecho, narrado por Rojas Marco, me ha hecho pensar sobre la crisis de paternidad que se observa de manera especial en las actuales sociedades, llamadas sociedades desarrolladas, y me invita a aproximarme al estudio o reflexión sobre la misma bajo las tres siguientes cuestiones, entre otras: ¿qué es lo que hace que un varón se constituya en padre de unos hijos?; ¿qué es aquello que se lo impide?; ¿qué y cómo se vinculan estas dos figuras: padre e hijo?

Desde Freud, y ya hace tiempo de esto, se viene "matando" la figura del "padre", símbolo de la autoridad. La teoría marxista sobre el patriarcado ha legitimado teóricamente la lucha contra el poder omnímodo del pater-familiae y ha promovido, como consecuencia, el proceso de liberación de la mujer. El matrimonio monógamo, atado por la indisolubilidad, era considerado por F. Engels como la forma más adecuada para transmitir y perpetuar la condición de la prepotencia del varón y la sumisión de la mujer.

Asistimos a tres fenómenos aparentemente contradictorios: un primer fenómeno lo podemos calificar, utilizando un término tomado del sociólogo Flaquer (1999) de "eclipsamiento" de la figura del padre, lo que sucede como consecuencia de un conjunto de factores, en los que destacamos los siguientes:

En primer lugar, la incorporación de la mujer al trabajo productivo y asalariado, lo que trae consigo su mayor autonomía; el acceso de la mujer a la educación superior, igualando o superando las tasas de los varones; las altas tasas de divorcio y los cambios de valores y de comportamientos que se vienen sucediendo en torno a la mujer y a la maternidad.

Un segundo fenómeno tiene que ver con la posición de centralidad que la mujer, sobre todo la mujer separada, divorciada, ha tomado respecto al papel a ocupar en la organización familiar, dando lugar a la "matrilinealidad" o "matrifocalización", fenómeno social no exento de efectos importantes para el desarrollo psicoeducativo de los hijos y para el aumento o "feminización de la pobreza".

El tercer fenómeno tiene que ver con la aparición, en el escenario de la crisis familiar, de la emergencia y reivindicación de un nuevo modelo o figura del padre varón, cuya explicación se puede encontrar en la "feminización de la sociedad". Así lo explica Elinor Lenz y Barbara Myerhoff (La feminización de América 1985): "Dado que el hombre y la mujer son criaturas complementarias, cualquier cambio en la maternidad inevitablemente genera una transformación adaptadora en la paternidad. En efecto, el nuevo padre es el producto más revolucionario y positivo de la feminización de la sociedad".

A pesar de lo dicho, estudios actuales demuestran que el patriarcado no ha perdido del todo su legitimidad (Alberdi 2002). Los códigos patriarcales no han perdido su vigencia en nuestra estructura psicológica y prácticas sociales. Aún estamos, y por mucho tiempo todavía, en el proceso de deslegitimación social del mismo. Perdura en el imaginario social el esquema básico de padre preñador, protector y proveedor que conforma el conjunto de normas y valores adscritos a muchas conductas de los varones en su cualidad de padres.

La parentalidad es más que un hecho biológico. Es un hecho cultural que acaece en un proceso de construcción y de definición social acerca de lo que se considera qué es la paternidad y la maternidad. Ambas realidades, paternidad y maternidad, se constru- 
yen en el entramado de las relaciones sociales. Una cualidad muy importante del ser humano es su capacidad de formar y mantener relaciones significativas, definidas culturalmente, sin las cuáles no se puede dar la supervivencia y el aprendizaje humano. Dentro del entramado de las relaciones interpersonales e intergrupales quedamos vinculados o adheridos unos a otros. En estos círculos de relaciones sociales significativas se construyen estas realidades: paternidad, maternidad, vinculaciones y sentimientos de pertenencia.

Los estudios e investigaciones sobre las relaciones de vinculación entre padres e hijos se han centrado más sobre las relaciones que se establecen entre madre e hijo que entre padre e hijo. En todo ello ha tenido una gran influencia el imaginario social que define, para el sentir colectivo, qué constituye y qué importancia tiene la paternidad y la maternidad en la educación y desarrollo del hijo. Esta influencia no se ha quedado sólo en el ámbito de los valores y de la educación, sino que ha trascendido a la esfera jurídica, protegiendo sesgadamente y de forma más especial las relaciones madre-hijo sobre las relaciones padre-hijo.

En el presente estudio me voy a centrar en los procesos que influyen y dificultan la construcción de la parentalidad y de la vinculación parento-filial, estudiada más desde el lado la paternidad que desde el lado de la maternidad, desarrollando los siguientes puntos:

1. La paternidad en el imaginario social. Elementos configuradores.

2. La vinculación como un haz de relaciones. Sentimientos básicos producidos por la misma.

3. La necesidad de un nuevo padre.

4. La paternidad y la desvinculación padrehijo en las situaciones de divorcio y en situaciones especiales.

5. Papel del mediador familiar.

El desarrollo del presente estudio se hace conjugando diversas perspectivas; tanto la del género como la sociológica y la psicosocial.

\section{LA PATERNIDAD EN EL IMAGINARIO SOCIAL. ELEMENTOS CONFIGURADORES.}

El imaginario social: Imaginario social o universos simbólicos son términos utilizados por la sociología para referirse al conjunto de signi- ficados, valores, normas y expectativas con las que comprendemos y definimos nuestras acciones y expectativas sociales. El imaginario social es una especie de "depósito" al que echamos mano para explicar y legitimar las acciones y fenómenos sociales, con cuyos elementos continuamos transmitiendo el devenir de la realidad social, a la vez que la reconstruimos y la reproducimos.

El ser humano es el único ser que puede dar significado a las cosas y a los acontecimientos. La cultura, propiedad exclusiva del ser humano, consiste precisamente en dar significado a todo lo que le rodea, en virtud de lo cual expresa sus sentimientos, define qué son las cosas, emite juicios, crea normas, reconoce lo que es digno de ser valorado y construye objetos, siempre significativos.

El Interaccionismo simbólico es una teoría que deriva de la sociología comprensiva de Max Weber, según la cual los seres humanos interaccionan entre sí a través de un medio, un intermediario: los símbolos y los signos. La interacción humana es social porque está simbólicamente mediada. La realidad social es significativa, es decir, es definida por los signos y símbolos que las personas utilizamos en nuestras interacciones; por eso la sociedad, la realidad social, debe ser comprendida en sus significados.

Berger y Thomas Luckmann (1973), desarrollan estos presupuestos teóricos utilizando el concepto de "construcción social de la realidad". Para los citados autores la realidad social tiene una doble vertiente: una objetiva: la realidad de las cosas en sí mismas, existentes fuera de la mente, tal como son, físicas y temporales; y una dimensión subjetiva, es decir, tal como es percibida, concebida y reedificada socialmente. Berger y Luckman utilizan el término reificación según el cual "el hombre es capaz de olvidar que él mismo ha creado el mundo humano, $y$, además, que la dialéctica entre el hombre, productor, y sus productos pasa inadvertida para la conciencia... La reificación es una modalidad de la conciencia, más exactamente una realidad de la objetivación del mundo humano que realiza el hombre" (págs. 116-177).

Así, pues, la realidad en su vertiente subjetiva es una construcción de la realidad social, un "constructo social" que "habita" de forma colectiva en el imaginario social y que a la vez se interioriza en el inconsciente colectivo e individual, produciendo siempre efectos sociales: comportamientos colectivos, roles, instituciones, 
normas, expectativas, juicios de valor, etc.

En este proceso de construcción social de la realidad intervienen, entre otros, los siguientes factores:

a) El uso del lenguaje. El lenguaje permite no sólo nombrar las cosas, sino definirlas y establecer relaciones con ellas.

b) Proposiciones teóricas en forma rudimentaria. Son esquemas explicativos de carácter pragmático que se relacionan directamente con acciones concretas. A este nivel corresponde los proverbios, las máximas morales, las sentencias, las leyendas y los cuentos.

c) Un tercer nivel lo constituyen las teorías explícitas que fundamentadas en argumentos elaborados, tratan de explicar las acciones y fenómenos humanos.

La paternalidad y la maternidad son realidades sociales que no escapan a la ley de la construcción social. Son también constructos sociales desarrollados por el imaginario social, en cuyas definiciones y desarrollo han intervenido muchos factores, como los biológicos, los económicos, los políticos e ideológicos, los religiosos y las creencias.

1.2. La paternidad definida desde la "ausencia", el carácter "periférico" y la "desvinculación biológica".

Los legisladores romanos establecieron una diferencia entre los progenitores, incuestionable para aquel tiempo, de carácter biológico, que se convirtió en lapidaria: "mater semper certa, pater semper incertus". Esta afirmación, desfavorable para el padre, hoy ha sido cuestionada por la ciencia, ya que el padre biológico puede ser determinado con certeza, como cierta es la madre.

Si la incertidumbre biológica de la paternidad ha quedado disipada, no ha sucedido así respecto a sus funciones tanto desde el punto de vista psicológico como social. Sus funciones y papeles han quedado recortados, disminuidos y cuestionados hasta tal punto que a muchas mujeres se les han planteado interrogantes como estos: ¿para qué sirve un padre?; ¿es verdaderamente necesario?

Desde el punto de vista sociológico, tres fenómenos explican, según Sullerot (1993), la ausencia y la pérdida de la importancia social del padre:

1) El rápido crecimiento del número de divorcios, al que es preciso añadir las separaciones entre las parejas no casadas.
2) La proporción de hogares monoparentales, que va en aumento, en los que los hijos viven mayoritariamente con la madre.

3) La proporción de hijos que antes de haber alcanzado los dieciocho años de edad se encuentran separados de sus padres. (Págs. 206-207).

La ausencia del padre es una característica que de alguna forma ha estado presente a lo largo de la historia, aunque de manera especial a partir de la Revolución Industrial. Previo a ésta, el padre era el productor dentro del territorio familiar, y convivía más con los hijos. A partir de la Revolución Industrial, el padre deja de ser productor y se convierte en asalariado, actividad que realiza en la fábrica, en la empresa, fuera del territorio familiar. El padre se convierte en proveedor de la familia, cuyas provisiones están fuera de los dominios de ésta.

Si aceptamos la definición que socialmente se hace de la figura del padre como el "ausente" y se compara con la que se hace de la madre, se deduce de ello dos aspectos que sobreabundan al carácter de ausencia: lo "periférico" y lo "desvinculante".

El concepto de paternidad, en contraposición con el de maternidad, se ha construido más sobre argumentos de carácter jurídico e ideológico que sobre razones de carácter psicoafectivo.

Vamos a centrar nuestra atención en el punto de vista biológico: la paternidad es una realidad reducida al ámbito de la necesaria contribución en el acto de la fecundación entre un óvulo y un espermatozoide, acabando aquí su contribución. Todo el proceso consecuente de dicha fecundación continúa en los ámbitos biofísico-psicológicos de la mujer gestante. En el transcurso del mismo, la mujer va construyendo desde dentro, vivenciando e interiorizando su nueva realidad de maternidad. Ello se realiza estableciendo una relación directa y multiforme con el hijo, en cuya dinámica juegan un papel importante los cambios físicos y hormonales de la mujer gestante, los movimientos del feto, los sentimientos, las xpectativas. Todo ello tiene una orientación bien clara y precisa: crear sentimientos de vinculación y de pertenencia que acompañarán a lo largo de la vida respecto a la madre y respecto al hijo.

Tanto la capacidad como el deseo de formar relaciones están asociados a la organización y funcionamiento de partes específicas del cere- 
bro humano, así como al equilibrio de los neurotransmisores. Estos son sustancias químicas que permiten la transmisión del impulso nervioso y sus conexiones. Así como el cerebro permite ver, oler, gustar, pensar y movernos, también es el órgano que nos permite amar o no amar. La empatía, el afecto, el deseo de compartir, la inhibición, la agresión, la capacidad de amar y ser amado y un sin número de características de una persona asertiva, operativa y feliz, están asociadas a las capacidades básicas de apego formadas en la infancia y en la niñez temprana.

El apego es un elemento básico en el campo del desarrollo infantil para explicar que el vínculo que une al niño con su madre, es producto de una serie de sistemas de conducta, cuya consecuencia previsible es aproximarse a la madre. El apego se refiere a un vínculo específico y especial que se forma entre madre e hijo o cuidador primario. Es una relación emocional perdurable, que produce seguridad y sosiego, y en la que está presente la pérdida o la amenaza de pérdida de la persona amada, lo que evoca una intensa ansiedad.

Los investigadores de la conducta infantil, como René Spitz (1935) y Bowlby (1958 y 1968) han venido a demostrar que una relación sólida y saludable con la madre o cuidador primario, se asocia con una alta probabilidad de crear relaciones saludables con otras personas, mientras que un débil apego parece estar asociado con problemas emocionales y conductuales a lo largo de la vida. Así, pues, la relación de apego entre madre-hijo ofrece el andamiaje funcional para todas las relaciones subsiguientes que el niño desarrollará en su vida. La relación más importante en la vida de un niño es el apego a su madre o cuidador primario, pues esta primera relación influye significativamente en el "molde" biológico y emocional, del que dependerán todas sus relaciones futuras.

Bowlby (1998) postula que "el vínculo que une al niño con su madre es producto de la actividad de una serie de sistemas de conducta, cuya consecuencia previsible es aproximarse a la madre, (pág. 249)"... el bebé va tomando conciencia muy lentamente de la figura materna y sólo al empezar a moverse con una cierta autonomía busca la compañía de esta". (Pág. 273). Bowlby enumera seis reacciones que dan lugar a una conducta de apego: el llanto, la risa, el seguimiento, el aferramiento, la succión y la llamada. (Pág. 284).
Desde el punto de vista de la paternidad, la relación o vínculo de apego con el padre, figura importante para el normal desarrollo evolutivo de todo hijo, no se ha conceptualizado en términos de importancia tanto como lo ha sido para el caso de la relación madre-hijo. Más aún, la contribución biológica del padre en la fecundación del hijo no es un hecho neutro. Es un hecho transformado por los significados que le da la cultura. ¿Qué significados son estos?

La respuesta a la pregunta formulada viene dada en gran parte por las mismas condiciones biológicas que acompañan a la relación padre-hijo, como son la no proximidad física y la exterioridad. De lo indicado se deduce que la relación de pertenencia y de vinculación que se establece entre el padre y el hijo, comparado con la que se establece entre la madre y el hijo, es más remota, menos próxima, más exterior y por ello reviste mayores dificultades para que sea asumida de forma psicoemocional, intima y personal.

Las diferencias señaladas son transformadas por la cultura creando un concepto de paternidad al que le acompañan tres características de índole ideológico, jurídico y social, que en la historia han estructurado socialmente las relaciones familiares en general y particularmente las que se establecen entre padre e hijo:

a) Ideológica: el padre se ha constituido históricamente como el pater-familiae, dueño de la prole y proveedor de la misma, símbolo de la autoridad y del poder. Es lo que se ha venido a llamar las tres $\mathrm{P}$ de la figura y funciones del padre: preñador, proveedor y protector.

b) Jurídico: El padre es el cabeza de familia, titular de la patria potestad, y de los derechos sobre la prole, al que van anexas obligaciones de carácter material e instrumental.

c) Social: El padre es comprendido socialmente como un ser periférico, definido por su exterioridad. El es siempre periférico, ajeno a las funciones nutrientes, emocionales y afectivas del hijo, en cuya vida se le permite entrar cuando alcanza cierta autonomía y emancipación.

De todo lo expuesto se puede concluir dos aspectos que vienen a clarificar tanto la construcción social de ambas realidades, maternidad y paternidad, como las expectativas, demandas y juicios de valor que, respecto a cada una de ellas, hace la sociedad a través del imaginario social. 
Primero: La relevancia del papel de la madre. Los estudios provenientes de las ciencias sociales y de las teorías psicológicas se han centrado mucho más, en detrimento de la figura del padre, en mostrar cómo la madre ejerce una importancia relevante en el desarrollo físico, psíquico y social del hijo, argumentando que la privación de este vínculo resulta dramática para el mismo. Este papel crucial de la madre, un tanto desmesurado a la hora de subrayar su función en el desarrollo del hijo, ha traído consigo dos efectos no deseados:

1) "La culpabilidad materna", (Clare 2002). Ésta no es más que un derivado de la gran trascendencia e influencia que se le atribuye a la madre en el proceso del desarrollo psico-afectivo del hijo, pues cuando dicha trascendencia e influencia no logran el efecto deseado, se vuelven en contra de la madre, convirtiéndola en "chivo expiatorio" de los males del hijo.

2) "La imagen borrosa" de un padre revestido de un cierto estado de carencia de afectividad, sensibilidad, de cariño y de ternura respecto a los hijos, y en posición de distancia por miedo a entorpecer el natural proceso del amor materno-filial.

Segundo: Concepción antitética entre paternidad y maternidad. Ambos conceptos se han construido de forma opuesta: La maternidad se ha construido sobre dos pilares: la sacralización de su entidad y funciones nutrientes, concediéndosele un valor crucial, y la naturalización , como si lo natural mereciera más sentido de realidad, y por ello no fuese construida socialmente, es decir, no fuese moldeable y transformable culturalmente.

La paternidad, por su parte, se ha construido en términos de importancia secundaria par el desarrollo psicológico del hijo. Partiendo del imaginario social y de la descripción de los hechos, se puede afirmar que al sagrado vínculo de la madre le sigue un padre carente, incompleto, prescindible y desvinculado de lo biológico. Mientras la madre no tiene que mostrar ser madre, porque es una acción natural, el padre, en cambio, ha de demostrar ser padre "si se lo trabaja mucho", pues ser un "buen" padre es una acción volitiva, elegida. Mientras el hombre elige la mujer con quién quiere tener hijos, la mujer elige si quiere o no tener hijos, lo que no deja de ser un poder en manos de la mujer con efectos psicosociales en la construcción de la paternidad.

\section{LA VINCULACIÓN PADRE-HIJO COMO UN HAZ DE RELACIONES Y EL SENTIMIENTO DE PERTENENCIA.}

\author{
2.1. Relaciones de vinculación. Caracte- \\ rísticas:
}

Si a partir de Freud se ha querido "matar" al padre como autoridad omnímoda y excluyente, hoy se puede afirmar que, en las consideraciones actuales que se le presta a la figura del padre y en el trato jurídico que se le otorga, la paternidad ha caído en "sospecha": la violencia, el abuso, la drogadicción y las conductas delictivas siguen siendo percibidas preferentemente con rostros masculinos, sin que se utilice otra variable para analizar el fenómeno que la variable género. Como consecuencia, muchos hombres han dejado de ser proveedores, protectores, e, incluso, progenitores. Despojados de sus funciones tradicionales y considerados todavía emocionalmente limitados, los varones aparecen hoy "desubicados" en el seno de la sociedad y de la familia, y por consiguiente inseguros y desmotivados para realizar sus funciones de padre.

El fenómeno de la sospecha es quizás una de las razones que explica el hecho de haber resaltado de forma llamativa en los estudios sobre la paternidad los efectos negativos de la privación de ésta y no, sin embargo, los efectos positivos de su presencia. Ello ha traído como consecuencia, según Kyle, (2001), una visión miope y distorsionada del desarrollo de la infancia y sus posibilidades.

Los estudios recientes sobre la importancia del padre en el desarrollo del hijo, vienen a reforzar su interés como recurso emocional importante. Rojas Marcos (2003) afirma que los hijos necesitan un modelo paterno para formar su yo, para consolidar su identidad, para desarrollar sus ideales y aspiraciones. En definitiva, se empieza a dar el peso debido a las funciones paternas y la importancia del componente emocional del padre en el desarrollo integral de los hijos.

Las funciones nutricias no son patrimonio de la maternidad. Son también propias de la paternidad. Los padres están capacitados para suministrar a los hijos, y estos así lo esperan, nutrición emocional: reconocimiento, amor y valoración. Los hijos, sintiéndose reconocidos, queridos y valorados por sus padres, son capaces de integrar normas y seguridad en proyectos personales coherentes. Considerando la vincu- 
lación como un proceso psico-emocional, éste no es patrimonio de la relación madre-hijo, aunque tenga su importancia particular. El padre también establece relaciones vinculantes fuertes y duraderas en los ámbitos psico-emocionales e identitarios.

La vinculación paterna y materna se ha de entender como un proceso, no tanto impuesto por imperativos biológicos cuanto como algo deseado y querido. En dicho proceso apreciamos diversas características que desarrollamos a continuación:

a) Las vinculaciones humanas en general, y las paterno-filiales en particular, tienen siempre una base emocional. Los humanos crecemos con un repertorio de emociones. Refiriéndonos al niño, podemos decir que al nacer tiene un repertorio de emociones básicas potencialmente completas y disponibles. Estas emociones van a tomar forma a través de las experiencias inmediatas, y tienen que ver con los procesos de vinculación con las figuras referenciales, como son los padres, y con las características emotivas de la persona que ejerce el vínculo. La calidad emotiva del vínculo se refleja en la unidad organizativa que el individuo tiene de sus emociones. Un mundo personal rico y equilibrado de emociones se sustenta y se desarrolla desde la infancia en la vinculación afectiva recibida de los progenitores.

b) Es de carácter bilateral y bidireccional entre dos sujetos: el padre o madre y el hijo, siendo siempre, dichas vinculaciones, mutuamente nutrientes para el desarrollo y fortalecimiento del yo de ambos actores.

c) Es interactivo, en cuanto que la relación, el contacto, la cercanía, el afecto, la ternura, el juego, etc., ejercen papeles importantes. En esta interactividad se juega, sobre todo por parte del hijo, el proceso de socialización y una satisfactoria percepción y valoración del propio yo, los llamados auto-conceptos y autoestima.

d) Las relaciones de vinculación parento-filial tienen lugar en la vida cotidiana, siendo la condición de lo cotidiano y no tanto lo esporádico o excepcional, lo que más ligazón crea y establece. Es en lo cotidiano de la vida donde se plantan las raices de la personalidad futura de los hijos y en donde los padres construyen y alimentan su identidad de padres.

e) Es dinámica: los procesos de vinculación paterno-filial están sometidos al devenir de los estadios propios del ciclo vital, en cuyo devenir acontecen unas etapas que se suceden unas a otras, pudiéndose destacar tres: la fusión, el desapego, la autonomía y el reequilibrio o reestructuración.

f) La vinculación parento-filial es vulnerable, en cuanto que está sometida tanto a influencias negativas provenientes de posibles condiciones disfuncionales de caracter psíquico-social de los adultos e hijos, como del medio-ambiente que pueda ser más o menos favorecedor $u$ hostil, pudiendo darse diversos tipos de vinculación: fuerte, segura, insegura, desorganizada, inestable y patológica.

2.2. Sentimiento de pertenencia. Aspectos básicos.

Junto a las relaciones vinculantes está el sentimiento de pertenencia al grupo familiar, al clan, a la tribu. El sentimiento de pertenencia es propio de todos los grupos primarios o grupos pequeños en los que las relaciones entre sus miembros son de carácter personal, directas y con una fuerte carga emocional. Este tipo de relaciones crea una conciencia del "nosotros" a la que sus miembros se adhieren en término de pertenencia, estructurando el sentido de la propia identidad. El ser humano se define también por el sentimiento de pertenencia que adquiere y le acompaña en su vida.

El sentimiento de pertenencia está sometido a la ley de la evolución y a la necesidad de la expansión, en cuanto que no se queda en los círculos familiares reducidos, sino que se abre a otros ámbitos o territorios como son los grupos de iguales, las asociaciones, los clubs, el vecindario, el pueblo, la región, la nación, etc.

La relación de pertenencia que se establece con el grupo familiar, en el que todo miembro tiene necesidad de ser incluido y reconocido, despierta por lo general y desarrolla a la vez tres sentimientos básicos:

1) Sentimiento de lealtad, de fidelidad, de adhesión, de inclusión, donde se impide o se niega la traición, la deslealtad, el abandono...

2) Sentimiento de protección y defensa de sus miembros, tendiendo a proteger siempre al más débil, al más vulnerable. 
3) Sentimiento de identidad: cada miembro de la unidad familiar se define a sí mismo por su relación con el grupo a través de los status y los roles que ocupa y realiza, y a través de las expectativas que percibe en el mismo el grupo. El grupo familiar es constructor de identidades. Cuanto más satisfactorio y gratificante es este sentimiento de identidad personal que se recibe del grupo, más saludable son las relaciones entre sus miembros.

El sistema de pertenencia humana es el medio por excelencia por el que cada ser humano construye un reconocimiento y un sentido de sí mismo, específico, único y singular, lo que le permite alcanzar un yo fuerte, seguro y consistente. Pertenecer a alguien, sobre todo en los primeros años de la vida, es reconocerse y tener un sentido específico y singular de sí mismo y de la existencia humana, a la vez que favorece el desarrollo de la sociabilidad y de la integración en los diversos espacios sociales.

\subsection{Las vinculaciones parento-filiales como un haz de relaciones:}

Las vinculaciones paterno-materno-filial se han de entender como un haz de relaciones que, estando más o menos integradas, se abren a los distintos subsistemas de los que consta el sistema familiar. Además de desarrollarse linealmente entre un subsistema y otro, por ejemplo el paterno-filial, o el de la fratridia, entre hermanos, sin embargo se estructuran a la vez de forma circular y sistémica, es decir, de forma interdependientes, con mutuas influencias, sean saludables, funcionales, patológicas o disfuncionales.

En las unidades familiares se reconocen los siguientes subsistemas de relaciones vinculantes y de pertenencia:

a) Conyugal o de pareja.

b) Parental: los esposos o pareja en cuanto padres.

c) Paterno/materno-filial.

d) Fratridia: relaciones entre hermanos.

e) Familia extensa: la relación que se establece con ambas familias de origen.

f) Redes sociales extrafamiliares: escolares, laborales, amigos, vecinos, pueblo, ciudad, etc.

En este haz de relaciones, propias del sistema familiar, las vinculaciones y los sentimientos de pertenencia adquieren peculiaridades y tonalidades diferentes según el subsistema familiar al que se refieran, sea el conyugal, el parental, el de la fratridia u otros, desarrollándose en su seno normas de comportamientos, obligaciones, lealtades y expectativas que son también diferentes. Todas estas vinculaciones y sentimientos de pertenencia estructuran tanto los subsistemas de la unidad familiar, en sí mismos considerados, como la misma unidad o entidad familiar, dándose un proceso circular y sistémico de influencia entre las partes o subsistemas y el todo familiar, no exento de tensiones y conflictos.

\section{NECESIDAD DE UN NUEVO PADRE:}

El estudio de las relaciones vinculantes desde la perspectiva paterno-filial, su importancia y complejidad, nos lleva a pensar en la necesidad de un nuevo padre. La paternidad ha dejado de ser algo preferentemente prescrito para convertirse en algo elegido y deseado. Los cambios culturales, que acaecen en torno a la paternidad, están demandando y alumbrando una nueva imagen de padre, que se abre paso en medio de un proceso que pudiéramos clasificar de "transición" y de "ambigüedad", en el que todavía nos movemos. Aún se necesita superar viejos esquemas y ocupar una posición de equidistancia frente a los modelos ideales impuestos por las fuerzas de la tradición y de la inercia y poder así construir personalmente nuevos modelos. Existe hoy una mayor conciencia de la trascendencia psicoeducativa de la paternidad y por eso pasa a ser una responsabilidad en la que se pone en juego tanto el destino y desarrollo personal de los hijos como los sentimientos de satisfacción o de fracaso de los propios padres varones. Se desea y se reivindica una nueva imagen de padre. ¿Qué nos sugiere esta nueva imagen de padre? Veamos algunos rasgos y consideraciones al respecto:

1) La nueva paternidad es una tarea a conquistar. No se da por supuesta. Exige un ejercicio consciente y voluntario de implicación personal, integrando de forma armónica la visión de las mujeres y la de los varones, es decir, tomando también como marco de referencia aspectos femeninos del cuidado y funciones nutrientes, hasta ahora proyectadas más hacia el lado de la mujer. La presencia cercana del padre continúa siendo una 
necesidad básica para las generaciones de hoy y las de mañana.

2) Ubicar reflexivamente en clave de "transición" el "estado de malestar" que actualmente sienten muchos varones al verse debilitados e inseguros en su tradicional rol de padre. Este estado de transición consiste en el paso, un tanto arduo y difícil, de un modelo deslegitimado $y$ anclado en las funciones tradicionales del paterfamiliae, a un modelo de padre que desarrolla las llamadas funciones nutrientes, emocionales - afectivas y de cuidado, consideradas hasta ahora como femeninas y maternales.

3) Asumir, como consecuencia del punto anterior, un proceso de "resocialización". Este consiste en la adopción y aprendizaje de la "alianza parental" o "paternidad compartida", o también "paternidad conjuntada" en términos simétricos. El primer espacio de socialización donde se aprende a ser padre, a desarrollar nuevas funciones y nuevas destrezas y habilidades, es la propia pareja. Alberdi (2002, opus cit.) considera a la pareja moderna como el principal agente socializador de los varones que comienzan a incorporarse al espacio doméstico. La relación de la pareja permite a ambos miembros la construcción y definición de los espacios, roles, funciones y tareas. La misma relación simétrica de la pareja activa en ambos miembros un proceso de revisión que impulsa tanto el camino a recorrer como la mutua autoestima para realizarlo.

4) El contenido de la citada resocialización implica el aprendizaje e interiorización de valores y atributos considerados hasta ahora como femeninos. Ser padre significa ser un poco madre, lo que en la vida práctica se traduce en la "paternidad compartida" o "coparentalidad". Implica también una nueva autodefinición por la que se abandona la idea incrustada en el inconsciente colectivo del padre "ayudante" que "colabora con" su cónyuge o progenitora y se reviste de la imagen de "protagonista" en el desarrollo de las funciones parentales. Ello trae consigo establecer prioridades frente a los imperativos que impone la esfera profesional y laboral, asumiendo los conflictos inherentes a esta opción.

\section{LA DESVINCULACIÓN PATERNO FILIAL EN SITUACIONES DE DIVORCIO Y SIMILARES.}

La desvinculación familiar en general, y la paterno - filial en particular, es un fenómeno complejo, de carácter psico-sociocultural, dominado por el dolor más o menos intenso, que siempre produce toda separación, sobre todo cuando previa a la ruptura se han gestado entre los desvinculados profundas y prolongadas relaciones de vinculación y de pertenencia.

Para el tema que nos ocupa, la desvinculación paterno - filial, conviene distinguir entre desvinculación como efecto del divorcio y desvinculaciones especiales.

\subsection{Desvinculaciones especiales:}

Por desvinculaciones especiales se entiende aquellas que, produciéndose en el entorno de la separación de una pareja con hijos, se generan en el seno de un conjunto de circunstancias sociales de precariedad, tanto de carácter económico, laboral y de vivienda, como de carácter psico-personal, afectiva y cultural, más o menos próximas a situaciones sociopsicopáticas.

Estas desvinculaciones corresponden por lo común a las llamadas familias desacopladas o desestructuradas, multiproblemáticas o disueltas, donde el abandono aparece como un movimiento previsible, unido a veces con la permanencia alternante e intermitente.

Dentro de estas desvinculaciones especiales podemos señalar y considerar las siguientes tipologías:

a) Desvinculación "vacía". Este tipo de desvinculación se da desde el estado de gestación del hijo o al poco tiempo de nacer, no dando lugar a establecer un mínimo de relaciones vinculantes entre padre e hijo. Es una desvinculación "vacía" de relaciones e intercambios afectivos. En el caso de la mujer se da cuando ésta abandona a su hijo en un portal u otros lugares apropiados para el hallazgo del bebé o lo entrega en adopción.

b) Desvinculación con "ausencia desconocida". Esta es producida por progenitores, por lo general varones, que al desarrollar sus fuentes de ingreso en circuitos delictivos y de corrupción, relacionados con la droga, las mafias y el dinero 
negro, se ven en la necesidad de huir y de ocultar la huida, lo que trae consigo una desvinculación por ausencia desconocida.

c) Desvinculación "intermitente" o "ambigua”. Este tipo de desvinculación es ocasionado por progenitores que tienen comportamientos de grave inestabilidad emocional y laboral, produciendo un círculo vicioso compuesto de tiempos de permanencia y tiempos de desvinculación. Estos no acaban de establecer una distinción clara entre el "adentro" y el "afuera".

Estos diversos tipos de desvinculación tienen en común un conjunto de circunstancias socio-psicopáticas que los genera o mantiene convirtiendo dichas relaciones vinculantes en débiles, inmaduras, ambiguas e inestables. Lógicamente, cada uno de estos modelos de desvinculación requiere un tratamiento singular, específico, e interdisciplinar según las características y las circunstancias que le acompañan. Ha de estar dirigido tanto al progenitor custodio como al hijo/a.

\subsection{Desvinculación post-divorcio:}

\subsubsection{Consideraciones generales:}

a) La desvinculación paterno - materno - filial, acaecida a partir de la separación o del divorcio, es siempre una situación dolorosa sobre todo para los hijos, trayendo consigo, por lo general, la transformación de la vida de éstos y la pérdida de la intimidad cotidiana con el progenitor que sale de la casa; se altera el orden familiar y los hijos se sienten inseguros y abandonados, al menos en un primer período, sobre todo cuando estos son infantes.

b) Los estudios realizados sobre experiencias clínicas (Richard Gardner, Universidad de Columbia) sobre los hijos de padres divorciados demuestran que los hijos continúan amando a sus padres de igual manera a pesar de la separación y del paso de los años. Así mismo continúan manteniendo buenas relaciones con ambos padres siempre y cuando no haya intención por parte del que ostenta la guarda y custodia de eliminar al otro progenitor de la relación.

c) La desvinculación post-divorcio no es equivalente entre los progenitores ni en- tre los padres e hijos. Para uno de los miembros de la pareja puede ser valorada como una liberación, cuando para la otra es considerada como una traición, o un caos para su vida. Para los hijos, sobre todo para los menores, y pensando desde una perspectiva subjetiva del psiquismo, puede ser considerada como una quiebra en el proceso de identidad.

d) Por lo general, la desvinculación post-divorcio y sus efectos en los hijos están en relación directa con los conflictos no resueltos de sus padres cuando estos confunden las relaciones que se establecen entre el equipo conyugal y el equipo parental. Esta confusión se alarga en la postruptura de la pareja complicando el ejercicio de las funciones parentales e impidiendo una reestructuración de la coparentalidad. Una pareja separada con hijos ha de disolver razonadamente las hasta ahora mutuas necesidades emocionales, propias del equipo conyugal que se rompe, cerrando el paso a la dependencia afectiva y abriendo la puerta a la mutua responsabilidad en el desarrollo de las funciones parentales: las socializantes, las nutrientes y las normativas.

e) El divorcio emocional no resuelto. Es otro factor muy importante a tener en cuenta en los procesos de desvinculación de postdivorcio. Se produce cuando los miembros de la pareja que se separan no elaboran, sobre todo por parte del miembro más afectado, la separación o ruptura emocional, y mantiene la confusión entre la conyugalidad, oficialmente no existente, y las relaciones de parentalidad. En tales circunstancias se dan altas probabilidades de que se produzcan estos tres fenómenos simultáneamente:

1) El alargamiento del conflicto en interminables y costosos trámites judiciales.

2) La involucración de la familia extensa en el conflicto, provocando o favoreciendo la desvinculación de los hijos respecto a la familia extensa del progenitor que inicia la separación.

3) La utilización de los hijos en contra del otro progenitor, interponiendo trabas y obstrucciones que impiden y debilitan las relaciones estables y armónicas que deben darse. 
f) La desvinculación paterno-filial en situaciones de post-divorcio está también en relación con las tipologías, ya desarrolladas en párrafos anteriores, como son la paternidad periférica y la paternidad ausente. Consecuentemente, la desvinculación que se produce no es otra cosa que la manifestación de lo que ya venía sucediendo, manteniéndose a los sumo un tipo de vinculación débil, insegura e inestable para los hijos.

\subsubsection{Algunas desvinculaciones "intere- sadas" con efectos nocivos y/o patológicos en los hijos:}

Las desvinculaciones "interesadas" con efectos nocivos o patológicos en los hijos son aquellas que son provocadas por lo común por parte de las parejas que están más afectadas emocionalmente, negándose a elaborar el divorcio emocional, que tienen problemas graves de alteración de conductas o que se sienten muy perjudicados/as económica y socialmente.

Sean cuales fueren las circunstancias arriba mencionadas, en las que se puede encontrar especialmente el progenitor custodio, se suele producir, entre otros, los siguientes fenómenos, todos los cuáles tienen en común quebrar y amputar la relación del hijo con el progenitor no custodio:

1) Utilizar implícita o explícitamente a los hijos como "hijos rehenes" expuestos, mediante un "lavado de cerebro" a una relación abusiva de escucha de mentiras y de supuestos defectos del padre no conviviente.

2) Incumplimiento interesado del régimen de visita, utilizando para ello seudoargumentos con los que se pretende ocultar comportamientos orientados a crear la obstrucción o la omisión por parte del progenitor no custodio, quien por cansancio o agotamiento desiste en continuar cumpliendo el régimen de visitas.

3) Interesada y calculada utilización del régimen de visitas respecto al progenitor no custodio para que, a cambio de la visita, salde facturas y cuentas, sean estipuladas o no vía sentencia judicial, o sean o no pendientes de sufragar. El padre que se ve utilizado como "pagador de facturas" terminará por cansarse y desvincularse progresivamente, abrién- dose la espiral del "padre irresponsable" con "mala imagen" ante sus hijos.

4) El síndrome de alineación parental. Especial interés tiene el síndrome de alineación parental (S.A.P.) en los procesos de desvinculación paterno-filial en situaciones de post-divorcio. Puede ser definido como "un trastorno caracterizado por el conjunto de síntomas que resultan del proceso por el cual un progenitor transforma la conciencia de sus hijos, mediante distintas estrategias, con objeto de impedir, obstaculizar o destruir sus vínculos con el otro progenitor, hasta hacerla contradictoria con lo que debería esperarse de su condición" (Aguilar. 2005, pág. 21).

El síndrome fue propuesto por Richard A. Gardner (1985) y objeto de la tesis doctoral de Ignacio Bolaños. Su manifestación primaria, según Bolaños, es la campaña de denigración de un hijo hacia uno de los progenitores, una campaña que no tiene justificación. El hijo está esencialmente preocupado por ver a un padre como totalmente bueno y al otro como el malo. El padre "malo" es odiado y difamado verbalmente, mientras que el padre "bueno" es amado e idealizado. Según Gardner, es el resultado de una combinación entre los adoctrinamientos de un padre "programador" y las propias contribuciones del niño para vilipendiar al padre "malo".

Gardner distingue tres tipos de alineación (ligero, moderado, severo) con diferentes intensidades de manifestaciones sintomáticas, que usualmente aparecen juntos en los niños afectados por el S.A.P. Según Bolaños (2000) las manifestaciones y tipos de alineación son las siguientes:

- Campaña de denigración. El niño está obsesionado con odiar a uno de los progenitores. Esta denigración a menudo tiene la cualidad de una especie de "letanía".

- Débiles, absurdas o frívolas justificaciones para el desprecio. EL niño plantea argumentos irracionales y a menudo ridículos para no querer estar cerca de su padre.

- Ausencia de ambivalencia. Todas las relaciones humanas, incluidas las paternofiliales, tienen algún grado de ambivalencia. En este caso, los niños no muestran sentimientos encontrados. Todo es bueno en un padre y todo es malo en el otro.

- Fenómeno del "pensador independiente". Muchos niños afirman orgullosamente que su 
decisión de rechazar a uno de sus progenitores es completamente suya. Niegan cualquier tipo de influencia por parte del padre aceptado.

- Apoyo irreflexivo al progenitor "alienante" en el conflicto parental. Habitualmente los niños aceptan incondicionalmente la validez de las alegaciones del padre aceptado contra el odiado, incluso cuando se les ofrece evidencia de que aquel miente.

- Ausencia de culpa hacia la crueldad y la explotación del progenitor "alienado". Muestran total indiferencia por los sentimientos del padre odiado.

- Presencia de argumentos prestados. La calidad de los argumentos parece ensayada. A menudo usan palabras o frases que no forman parte del lenguaje de los niños.

- Extensión de la animadversión a la familia extensa y red social del progenitor "alienado". El niño rechaza a personas que previamente suponían para él una fuente de gratificaciones psicológicas.

\section{PAPEL DEL MEDIADOR FAMILIAR ANTE LOS PROCESOS DE DESVINCULACIÓN PATERNO-FILIAL EN SITUACIONES DE POST-DIVORCIO.}

La mediación familiar es un procedimiento alternativo de resolución de conflictos que, aunque no sustituye ni desplaza los procesos jurídicos tradicionales, tiene por finalidad, entre otras consideraciones, evitar la judicialización de las relaciones emocionales y afectivas, propias del ámbito conyugal-familiar, e implicar a las partes en el conflicto para que, removiendo los obstáculos emocionales y de otra índole, alcancen los mejores acuerdos, $y$ formulen aquellas reglas que mejor beneficien a los hijos en primer lugar y a la propia pareja en segundo lugar. De esta forma, la mediación familiar pretende que no sea un tercero, el abogado, el juez, quien tome las decisiones respecto al ejercicio de las funciones parentales, sino que la continuidad en éstas en la situación de post-separación sea acordada y consensuada por las partes interesadas, la propia pareja y/ o los propios padres.

La mediación familiar, como procedimiento alternativo de resolución de conflictos, tomó forma estructurada en E.E.U.U. en los años 70 del siglo pasado, y se ha extendido por la inmensa mayoría de los países desarrollados, siendo legitimada legalmente por los Gobiernos de los mismos.
En el caso de España, no existe aún una Ley de Mediación de carácter estatal que regule su ejercicio. No obstante, la Ley $15 / 2005$, de 8 de julio, por la que se modifican el Código Civil y la Ley de Enjuiciamiento Civil en materia de separación y divorcio establece "la mediación (familiar) como un recurso voluntario alternativo de solución de litigios familiares por vía de mutuo acuerdo con la intervención de un mediador, imparcial y neutral". ..."De esta forma, las partes pueden pedir en cualquier momento al juez la suspensión de las actuaciones judiciales para acudir a la mediación familiar y tratar de alcanzar una solución consensuada en los temas objeto de litigio" (Exposición de Motivos).

Son los Parlamentos de las Comunidades Autónomas del Estado Español, por ser depositarias de las transferencias sociales en materia de familia, las que vienen legislando el ejercicio profesional de la mediación familiar: objeto y ámbito, condiciones y requisitos de los mediados, condiciones para la habilitación de los mediadores, fases del proceso mediador, etc.

Hasta la actualidad existen seis Comunidades Autónomas del Estado Español que han aprobado y publicado sus respectivas leyes de Mediación Familiar, en las que se recoge preceptivamente la necesidad de la formación específica para poder actuar como mediador familiar: Ley 1/2001 de 15 de marzo de Mediación Familiar de Cataluña; Ley 4/2001 de 31 de mayo, Reguladora de Mediación Familiar en Galicia; Ley 7/2001 de 26 de noviembre, Reguladora de Mediación Familiar de la Comunidad Valenciana; Ley Canaria 15/2003, de 8 de abril de Mediación Familiar, reformada por la Ley $3 / 2005$ de 23 de junio, para la modificación de la Ley $15 / 3003$, de 8 de abril, de Mediación familiar, la Ley 4/2005 de 24 de mayo, del Servicio Social Especializado de Mediación Familiar de la Comunidad Autónoma de Castilla-La Mancha y la Ley 1/2006, de 6 de abril, de Mediación familiar de Castilla y León.

La mediación familiar tiene efectos funcionales de gran interés para las partes implicadas y para la misma sociedad en su conjunto. Permite que la pareja en conflicto logre "desatarse", separarse, emocionalmente, y "unirse" como padres, manteniendo la coparentalidad y las funciones que le son propias, lo que sin duda redundará beneficiosamente en el tejido social, evitando en los hijos posibles patologías sociales. 
Así mismo, la mediación familiar permite que las partes en conflicto no entren o salgan del orden de la confrontación judicial clásica, en el que priman las figuras del vencedor y del vencido, haciendo posible que las mismas puedan seguir relacionándose en el futuro, por cuanto tienen intereses en común, como son especialmente los hijos.

Una de las figuras importantes en el proceso de mediación es el mediador familiar. Es un tercero, cualificado profesionalmente, que actúa siempre a petición de las partes y moviliza, bajo los principios de la confidencialidad, neutralidad e imparcialidad, el procedimiento en condiciones tales que las partes en conflicto lleguen a los acuerdos más beneficiosos para ellos y los hijos, utilizando para su consecución las técnicas de resolución de conflictos.

El mediador familiar interviene con mucha frecuencia en situaciones de desvinculación paterno-materna infantil, como sucede en temas relacionados con el régimen de visitas o la custodia monoparental o compartida. Por ello, el mediador ha de auscultar qué tipo de desvinculación se está produciendo para poder ayudar a resituar y a crear las reglas y acuerdos que mejor garanticen el bien de los hijos, sus necesidades $y$ vinculaciones afectivas, las funciones parentales y los valores que han de orientar y sustentar la acción educativa-familiar. El papel del mediador familiar referido a las situaciones de desvinculación parterno-filiales es muy importante y trascendental, pudiéndose concretar en los siguientes aspectos o funciones:

a) Tener muy en cuenta las vinculaciones y sentimientos de pertenencia habidos en la historia de la familia objeto de la mediación, valorando los aspectos fuertes y débiles de los mismos y su incidencia tanto en el desarrollo personal de de los hijos como en el tejido de la unidad familiar. La familia debe mantenerse lo suficientemente ligada como para que los hijos no pierdan el sentimiento de pertenencia y de seguridad y, a la vez, lo suficientemente flexible como para acomodarse a los cambios que imponen la separación o el divorcio. El mediador familiar ha de tener en cuenta estos referentes a la hora de que los mediados elaboren sus acuerdos en beneficio de los hijos.

b) Orientar la acción mediadora para que las competencias del subsistema parental se deslinden, se diferencien, de las fronteras habidas hasta ahora con las relaciones conyugales que se extinguen, y consecuentemente se conserven con el menor tropiezo entre ambos ámbitos. De esta forma los padres podrán continuar cumpliendo las funciones socializadoras, nutricias y normativas.

c) Estimular la capacidad de acuerdos de las partes. La resolución de la crisis del divorcio está estrechamente ligada a la capacidad de los padres para generar acuerdos. Los padres que desde el principio de la separación logran acuerdos hacen posible que los hijos alcancen una mayor competencia social y mantengan sus vinculaciones y sentimientos de pertenencia y de seguridad personal.

d) Arropar la crisis de la desvinculación marital. Reconocer y valorar los esfuerzos que el miembro de la pareja más afectada por la separación hace por elaborar el divorcio emocional, arropando la crisis de la desvinculación marital, resituándola en el contexto del duelo, de tal manera que esta experiencia dolorosa no estanque o bloquee los procesos de elaboración de los acuerdos.

e) Prestigiar y honorificar la imagen y la jerarquía de los padres. Ayudar a lo progenitores a elaborar acuerdos orientados a mantener y a prestigiar ante los hijos la imagen y jerarquía de los mismos como padres, conjugando y armonizando los criterios y pautas educativas. De esta forma se evitarán las alianzas interesadas entre padres e hijos, y las interesadas y solapadas desvinculaciones de los hijos respecto al progenitor no custodio.

f) Propiciar la coparentalidad y la elaboración del "plan parental", suscitando y favoreciendo, mediante la creación de relatos comunes, todos aquellos acuerdos que hagan posible en el mayor grado deseable la co-parentalidad antes que la custodia monoparental, para lo cual se les facilitarán las condiciones adecuadas para que los progenitores elaboren de forma acordada el llamado "plan parental".

g) Favorecer la red familiar. Introducir en el proceso de acuerdos aquellas condiciones que hagan posible que los hijos no 
se desvinculen de la red familiar y social. Esta red de apoyo es muy necesaria y eficaz cuando acepta la separación de los cónyuges o pareja, no toma partido, brinda ayuda emocional y financiera, sostiene al padre custodio en sus funciones parentales, no minusvalora al padre no custodio y se preocupa sobre todo del bienestar y equilibrio emocional de los niños.

h) Facilitar el acceso a los hijos a favor del padre no custodio, ayudando a crear las condiciones adecuadas para que el progenitor custodio lo haga posible dentro de los acuerdos que se van elaborando.

\section{A MODO DE CONCLUSIÓN.}

La mediación familiar es un método de resolución de conflictos que interviene en un escenario familiar complejo, transido por la disolución y la separación de vínculos emocionales y afectivos, los cuales a su vez tienen que ver con procesos identitarios de los miembros afectados. En este escenario, la figura del padre y sus funciones familiares se pueden ver cuestionadas, sin que haya mediado previamente una posición crítica al respecto, más bien se corre el riesgo de que en dicho escenario se reproduzcan, a modo de resonancias, las construcciones sociales que en torno a la paternidad existen en el imaginario social, dándose lugar a una sesgada valoración de una de las figuras parentales en detrimento de la otra y también a una inadecuada intervención mediadora.

Una reflexión atenta y sistemática sobre la práctica de la mediación familiar nos permite observar cómo en las situaciones de ruptura conyugal se ponen en juego los sentimientos de pertenencia así como los procesos de apego y de desvinculación familiar, sobre todo los referidos a los que se producen entre padre e hijos, pudiendo contrastarlos con la aparición en el escenario social de una nueva imagen de padre, demandada por la sensibilidad social actual.

En este marco brevemente descrito es en el que hemos querido plantear el papel de la mediación familiar y más especialmente las funciones del mediador en orden a encontrar de manera razonada los términos de su actuación y de su debida equidistancia. Así pues, la práctica de la mediación familiar, asumida desde la perspectiva de la reflexión y observación sistemática, se nos presenta como un lugar apropiado en el que surgen nuevas cuestiones, nuevos requerimientos, nuevas demandas, cuyas respuestas redundarán en el desarrollo de la mediación en general y de la mediación familiar en particular.

\section{REFERENCIAS:}

Aguilar, M.J. (2005). S.A.P. Hijos manipulados por un cónyuge para odiar al otro. Códoba. Almuzara.

Berger, P. Thomas Luckman (1979). La construcción social de la realidad. Argentina. Amorrortu.

Bolaños, I (2000). Estudio descriptivo del síndrome de alineación parental en procesos de separación y divorcio. Diseño y aplicación de un programa piloto de mediación familiar. Tesis doctoral. Universidad autónoma de Barcelona.

Bowlby, J (1998). El apego. Barcelona. Paidós.

Clare, A (2002). Hombres. La masculinidad en crisis. Madrid. Taurus.

Flaquer, LI. (1999). La estrella menguante del padre. Barcelona. Ariel.

Gardner, R.A. (1991). Legal and psychotherapeutie approaches to the three types of Parental Alienation Syndrome families. Court Review of American Judges Association, 28(1), 14-21.

Gardner, R.A. (1988b). The parental alienation syndrome: A guide for mental health and legal professionals. Creskill, NJ: creative therapeutic.

Kyle, D (2001). El rol del padre. Buenos Aires. Ediciones B. Argentina.

Rojas Marcos, L. (1999). La pareja rota. Familia, crisis y superación. Madrid. Espasa, bolsillo, pág. 38.

Rojas Marcos (2003). La pareja rota. Madrid. Espasa Calpe.

Sullerot, E. (1993). El nuevo padre. Un nuevo padre para un nuevo mundo.Barcelona. Documentos. 